\title{
LESSON 96
}

Memo 5

PAPER: A5 $(210 \times 148 \mathrm{~mm})$.

TARGET TIME: 7 minutes.

Take one carbon copy.

\section{Postcard 4}

TODAY'S DATE

TARGET TIME: 5 minutes.

Display 9

PAPER: A5 (148 × $210 \mathrm{~mm})$.

TARGET TIME: 15 minutes.

Put in the leader dots.

Display 10

PAPER: A5 (148 × $210 \mathrm{~mm})$.

TARGET TIME: 10 minutes.

Put in the leader dots.
From Headmaster To All staff Date To-day's date Subject C.S.E. and G.C.E. entry Will all staff please note that there will be a general Staff Meeting in the staff Room at 1600 hours on Monday next. (Paragraph) Following the staff Meeting there will be a meeting of all staff who take the 5 th forms and the entry recommendations for both C.S.E. and G.C.E. will be made. Heads of Department are requested to attend even if they do not take 5th forms. Form Tutors are requested to bring along the reports for their forms.

From The modern $r$ uncture Stove, 59 High Street, Yeail 509 3NB. The dering auite you ordered last mouth is now aw airing inspection. Should you decide to have the suite delivened without vienong it would you kindly 'phone Yeouil 5646 and ask for mr. Eveto. Please note that this strore closes early on Wedreoday but remanis of an unti 8.00 rum on Friday.

To Mr. R. Summers, HightEms, ash HU, Yeoull So2 7 A

\section{KINDS OF SEED.}

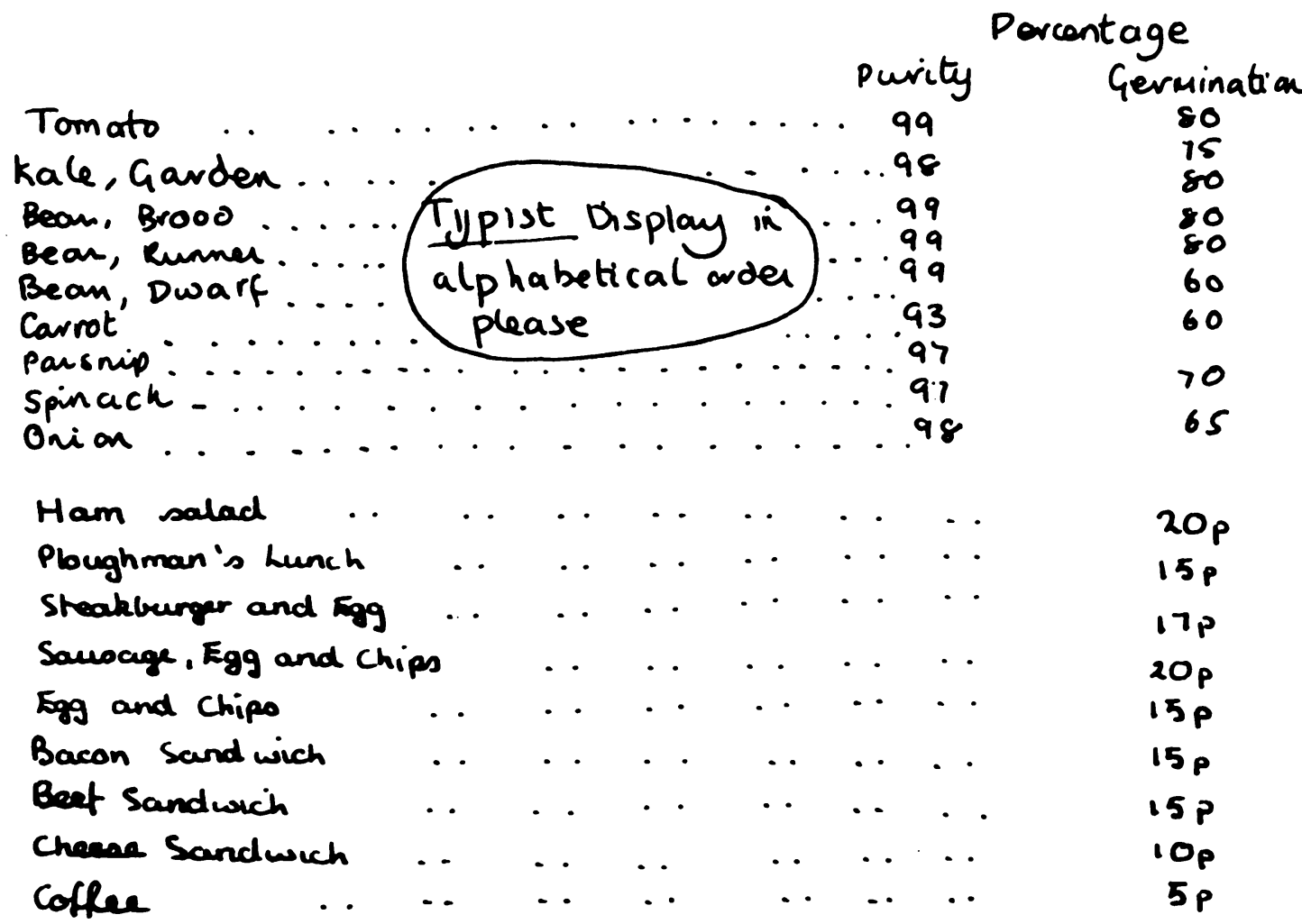

UNIT 24

LESSON 96 